Table 1. Outcomes of 6-month treatment with FO

\begin{tabular}{lccc}
\hline & Baseline & 6 months & p value \\
\hline Physical activity & $132(66,594)$ & $594(396,2376)$ & 0.07 \\
IPAQ & $0(0,0)$ & $0(0,0)$ & 1.00 \\
Walking, MET-min/week & $0(0,0)$ & $0(0,0)$ & 0.32 \\
Moderate, MET-min/week & & & \\
Vigorous, MET-min/week & & & \\
Foot pain & $4.6(3.1,7.4)$ & $2.8(1.1,4.7)$ & 0.02 \\
VAS score & $1.5(1.1,2.3)$ & $1.1(0.9,1.5)$ & 0.07 \\
ADL & & & \\
HAQ & $21.4(20.7,22.7)$ & $20.7(19.3,22.1)$ & 0.89 \\
Body composition & $31.1(24.2,37.6)$ & $32.9(26.3,36.5)$ & 0.82 \\
BMI, kg/m & $5.2(4.8,5.3)$ & $5.2(5.0,5.2)$ & 0.61 \\
BFP, \% & & & \\
SMI, kg/m² & & & \\
\hline
\end{tabular}

IPAQ: International Physical Activity Questionnaire, VAS: visual analog scale, ADL: activities of daily living, HAQ: Health Assessment Questionnaire, BMI: body mass index, BFP: body fat percentage, SMI: skeletal muscle mass index

Data are presented as median (lower quartile, upper quartile)

Conclusion: The prevalence rate of sarcopenia in patients with RA with foot deformities was much higher than previous reported ${ }^{1)}$. However, 6 months of treatment with a FO not only reduced foot pain but also maintained physical activity and muscle mass. Physical therapy has recently been recommended for patients with inflammatory arthritis. physical activity and muscle mass of patients with RA and concurrent foot deformities may be increased by combining physical therapy with orthotic treatment

References:

[1] Tada M, et al. Matrix metalloprotease 3 is associated with sarcopenia in rheumatoid arthritis - results from the CHIKARA study. Int $\mathrm{J}$ Rheum Dis. 2018; 21 (11): 1962-9.

[2] Hennessy K, et al. Custom foot orthoses for rheumatoid arthritis: A systematic review. Arthritis Care Res (Hoboken). 2012; 64 (3): 311-20.

Acknowledgments: This work was supported by JSPS KAKENHI Grant Numbers JP19K11420.

Disclosure of Interests: None declared

DOI: 10.1136/annrheumdis-2020-eular.3143

\section{THU0569 PHYSICAL ACTIVITY IN AXIAL SPONDYLOARTHRITIS AND RHEUMATOID ARTHRITIS: A CROSS-SECTIONAL STUDY IN A SOUTH-EAST ASIAN COHORT}

A. Khor ${ }^{1}$, C. T. Ng ${ }^{1,2}$, W. Fong ${ }^{1,2,3} .{ }^{1}$ Singapore General Hospital, Rheumatology and Immunology, Singapore, Singapore; ${ }^{2}$ Duke-NUS Medical School, Singapore, Singapore; ${ }^{3}$ Department of Medicine, Yong Loo Lin School of Medicine, National University of Singapore, Singapore, Singapore

Background: Axial spondyloarthritis $(\mathrm{AxSpA})$ and rheumatoid arthritis $(\mathrm{RA})$ are two common rheumatic diseases that can result in joint damage and deformities, leading to reduced physical function and quality of life. Physical activity (PA) and exercise have been shown to improve general well-being and reduce cardiovascular risk in patients with AxSpA and RA, and are part of the non-pharmacological management in the EULAR guidelines. Despite this, PA levels are reduced in $\mathrm{AxSpA}$ and RA patients ${ }^{1,2}$. In addition, it has also been reported that Asians have lower levels of $\mathrm{PA}^{3}$.

Objectives: This study aims to examine the patterns of PA in a multi-ethnic Asian cohort.

Methods: This was a cross-sectional study conducted between May 2016 and Jan 2017. Consecutive patients with AxSpA and RA were recruited at an outpatient rheumatology clinic at Singapore General Hospital, the largest tertiary hospital in Singapore. Controls were based on a previous cross-sectional study ${ }^{4}$. PA was assessed using the Global Physical Activity Questionnaires (GPAQ) developed by the world health organization $(\mathrm{WHO})^{5}$.

Results: $74 \mathrm{AxSpA}$ and $69 \mathrm{RA}$ patients were recruited and compared to 886 controls. AxSpA patients were younger (median age [IQR], 37.0 [26.3] years) and predominantly male $(75.7 \%)$, while RA patients were the oldest (median age [IQR], 59.0 [16.5] years) and predominantly female (81.2\%). BMI was similar between all three groups. RA patients had more comorbidities (such as hypertension, hyperlipidemia, diabetes mellitus) compared to AxSpA patients and controls.

All three groups had similar proportion of participants meeting $\mathrm{WHO}$ recommendations for $\mathrm{PA}(\mathrm{AxSpA}=77.0 \%, \mathrm{RA}=79.7 \%$, controls $=83.1 \%, \mathrm{p}=0.35)$ and median (IQR) time $(95 \% \mathrm{CI})$ of PA per day [60 (107.1) vs 57.9 (122.9) vs 51.4 (94.3), $p=0.93$ ). More AxSpA patients had a high level of sedentary activity compared to $\mathrm{RA}$ or controls $(\mathrm{AxSpA}=56.8 \%, \mathrm{RA}=23.2 \%$, controls $=7.2 \%, \mathrm{p}$ $<0.01)$. When comparing AxSpA and RA patients with inactive disease or in remission versus active disease, levels of PA did not differ between the 2 groups $(p=0.33)$.

Conclusion: Levels of PA did not differ significant between AxSpA and RA patients compared to the general population, and disease activity levels did not affect the level of PA in patients with AxSpA and RA. Of note was that patients with AxSpA and RA demonstrated higher levels of sedentary activity compared to the general population. Improving PA and decreasing sedentary activity could reduce the cardiovascular risk, especially in patients with $R A$.

References:

[1] Summers G, Booth A, Brooke-Wavell K, Barami T, Clemes S. <p>Physical activity and sedentary behavior in women with rheumatoid arthritis: a comparison of patients with low and high disease activity and healthy controls</p>. Open Access Rheumatol Res Rev. 2019; Volume 11:133-142. doi:10.2147/oarrr.s203511

[2] Sundstrom B, Ekergård $\mathrm{H}$, Sundelin G. Exercise habits among patients with ankylosing spondylitis. Scand J Rheumatol. 2002;31(3):163-167. doi: $10.1080 /$ rhe.31.3.163.167

[3] Lip GY, Luscombe C, McCarry M, Malik I, Beevers G. Ethnic differences in public health awareness, health perceptions and physical exercise: implications for heart disease prevention. Ethn Health. 1996;1(1):47-53. doi:10.1080 /13557858.1996.9961769

[4] Win AM, Yen LW, Tan KH, Lim RBT, Chia KS, Mueller-Riemenschneider F. Patterns of physical activity and sedentary behavior in a representative sample of a multi-ethnic South-East Asian population: A cross-sectional study. BMC Public Health. 2015;15(1):1-11. doi:10.1186/s12889-015-1668-7

[5] Bull FC, Maslin TS, Armstrong T. Global physical activity questionnaire (GPAQ): Nine country reliability and validity study. J Phys Act Heal. 2009;6(6):790-804. doi:10.1123/jpah.6.6.790

Disclosure of Interests: Andrew Khor: None declared, Chin Teck Ng: None declared, Warren Fong Consultant of: Abbvie, Janssen, Novartis, Speakers bureau: Abbvie, Janssen, Novartis

DOI: 10.1136/annrheumdis-2020-eular.3229

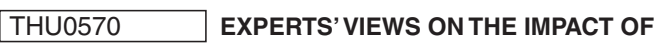 REHABILITATION FOR PATIENTS WITH RHEUMATOID ARTHRITIS IN AUSTRIA}

C. Oppenauer ${ }^{1}$, E. Böttcher ${ }^{2}$, G. Eberl ${ }^{3}$, A. Falkenbach ${ }^{4}$, W. Habelsberger ${ }^{5}$, J. Kirchheimer ${ }^{6}$, W. Kullich ${ }^{7}$, E. Mur ${ }^{8}$, C. Oliveira-Sittenthaler ${ }^{9}$, G. Stummvoll ${ }^{10}$, C. Wiederer ${ }^{11}$, H. Zeindler ${ }^{12}$, V. Nell-Duxneuner ${ }^{13} .{ }^{1}$ Medical University of Vienna, Institute for Outcomes Research, Vienna, Austria; ${ }^{2}$ Humanomed Zentrum Althofen, Althofen, Austria; ${ }^{3}$ Kurzentrum Ludwigstorff Ges.mbH \& Co KG, Bad Deutsch-Altenburg, Austria; ${ }^{4}$ Rehabilitationszentrum Bad Ischl, Bad Ischl, Austria; ${ }^{5}$ Franziskus Spital, Wien, Austria; ${ }^{6}$ Thermenresort Warmbad Villach, Villach, Austria; ${ }^{7}$ Ludwig Boltzmann Department for Rehabilitation, Saalfelden, Austria; ${ }^{8}$ Das Allgemeine öffentliche Landeskrankenhaus InnsbruckUniversitätsklinik, Institit für Physikalische Medizin und Rehabilitation, Innsbruck, Austria; ${ }^{9}$ SKA der PVA Laab im Walde, Laab im Walde, Austria; ${ }^{10}$ Malcherhof Baden, Baden, Austria; ${ }^{11}$ Klinikum am Kurpark Baden, Baden, Austria; ${ }^{12}$ Klinikum Bad Gastein, Bad Gastein, Austria; ${ }^{13}$ Österreichische Gesundheitskasse - Klinikum Peterhof Baden, Baden, Austria

Background: Rehabilitation methods and standards for patients with rheumatoid arthritis (RA) have significantly changed due to more efficient medication improving the course of the disease. Therefore, physical activity, participation, disease management and patient education are most important goals in rehabilitation of patients with RA.

Objectives: Aim of this study was to evaluate the significance and impact of rehabilitation methods according to the subjective attitudes and views of experts and professionals in the field of RA. Opinions of members of the task force (TF) "Rehabilitation" of the Austrian Society of Rheumatology (ÖGR) were compared to the estimation of the other members of the ÖGR.

Methods: All members of the ÖGR were invited to participate in an online survey to rate the impact of rehabilitation for patients with RA between 0 (no impact) and 10 (high impact). Besides sociodemographic and experience related data about the experts and professionals, two main issues were investigated: (1) Impact of rehabilitation related to specific interventions (2) Impact of rehabilitation methods for patients with RA according to different disease and treatment points.

Results: 129 members (50\% male, 50\% female) of the ÖGR participated in the online survey. 12 persons were members of the TF "Rehabilitation" of the ÖGR $11(8.6 \%)$ respondents were general physicians, 66 (51.6\%) specialists in internal medicine with further expertise in rheumatology, $15(11.5 \%)$ specialists in internal medicine, $14(10.9 \%)$ specialists for physical medicine with further expertise in rheumatology, $2(1.6 \%)$ specialists in orthopaedics, $13(10.2 \%)$ health professionals and 7 (5.5\%) persons were from other profession categories such as researchers for example. The majority of respondents $(80 \%)$ worked already 